Check for updates

Cite this: RSC Adv., 2017, 7, 26377

Received 17th March 2017

Accepted 3rd May 2017

DOI: 10.1039/c7ra03162a

rsc.li/rsc-advances

\section{Synthesis and application of a MOF-derived NiaC catalyst by the guidance from an in situ hot stage in TEM†}

\author{
Dan Xu, Ying Pan, Mingyi Chen, Qinying Pan, Liangkui Zhu, Ming Xue, Daliang Zhang, * \\ Qianrong Fang (D) and Shilun Qiu*
}

Metal-organic frameworks (MOFs) as a class of crystalline porous solids have attracted considerable attention due to their promising potential performance. MOFs have been recently proved to be ideal sacrificial templates for fabricating their respective derivatives by changing the thermal conditions. However, uncertainties still remain, and the direct observation of transition from MOF to metal nanoparticles (NPs) dispersed in carbon matrix is an important and crucial task for the development of MOF-derived materials. Here, transmission electron microscopy (TEM) combined with in situ hot stage technique was applied to directly observe the transition from MOF to metal NPs. Through in situ TEM experiment, the nanocrystals of $\mathrm{Ni}$-ntca precursor (ntca $=1,4,5,8$-naphthalenetetra carboxylic acid) are pyrolyzed under the temperature of 400,500 , or $600{ }^{\circ} \mathrm{C}$ to synthesize abundant Ni-NPs embedded in hierarchically porous carbon composites. Furthermore, the as-prepared samples show high catalytic activity and stability for the reduction of 4-nitrophenol (4-NP) to 4-aminophenol (4-AP) with $\mathrm{NaBH}_{4}$ in aqueous conditions. More importantly, Ni@C-600, which has nickel contents of $72.8 \%$, shorten the reduction time to $3.5 \mathrm{~min}$ with high conversion of nearly $100 \%$. When the catalyst is applied to recycle after being separated from the reaction by an extern magnet, it still keeps high conversion of $92 \%$ after 8 cycles, addressing the high stability of the composites. It is believed that these results will further facilitate the exploration of the technique of the TEM combined with in situ hot stage as a powerful tool in the carbonization of MOFs to obtain MOF-derived materials with different applications.

\section{Introduction}

Metal-organic frameworks (MOFs), also have been called porous coordination polymers (PCPs), consist of metal ions or metal-containing clusters in combination with a continuously expanding library of multi-functional organic ligands..$^{1-6}$ Their fascinating feature of high porosity as well as large surface areas, made them useful for applications in gas storage and separation, ion exchange, catalysis, sensing, and electrochemical capacitance over the past two decades. ${ }^{7-12}$ Recently, MOFs have been proved to be ideal sacrificial templates for fabricating their respective derivatives by changing the thermal conditions in the different atmosphere.

In 2008, Xu's group synthesized nanoporous carbon materials by pyrolyzing MOF-5 and furfuryl alcohol (FA) for the first time. They opened the gate of carbonizing MOFs and developed the applications of MOF-derived nanomaterials. ${ }^{13}$ After that, the use of MOFs as templates to create nanoporous carbon

State Key Laboratory of Inorganic Synthesis and Preparative Chemistry, Jilin University, Changchun, 130012, China. E-mail: sqiu@jlu.edu.cn

$\dagger$ Electronic supplementary information (ESI) available. See DOI: $10.1039 / \mathrm{c} 7 \mathrm{ra03162a}$ materials, nanostructured metal oxides and carbon-metal hybrids have been quickly developed. ${ }^{14-17}$ Liu's group prepared carbon-cobalt hybrid materials through the thermolysis of the Co-ZIF precursor at $750{ }^{\circ} \mathrm{C}$ which has been explored as a good catalyst for oxygen reduction reaction (ORR). ${ }^{18}$ The porous carbon-based nanomaterials prepared by this novel MOFtemplated route possessed many advantages such as large internal surface area, high crystallinity, tailorable porous structure and tuned in modification, and more and more researchers focused on fabricating desired catalysts derived from MOFs precursors. ${ }^{19,20}$

There were various MOF-templated carbon-based nanomaterials synthesized via a choice of suitable MOF templates, pyrolysis atmosphere and temperature. Zhang's group employed zinc-nickel-terephthalate frameworks as precursors to prepare a carbon-nickel hybrid material. By adjusting the ratio of $\mathrm{Zn} / \mathrm{Ni}$, the catalysts with densely populated metal sites were applied in the converting of 4-nitrophenol. ${ }^{21}$ In addition, the use of other metal-based MOFs (Fe, Co, Cu etc. $)^{17,22-25}$ as templates has promoted the development of the catalytic field. During the process of carbonization, the carbon generated from the organic linkers coated metal NPs and further prevented them from aggregating. Moreover, the in situ generation 
methods makes metal NPs more uniformly and stably dispersed in porous carbon matrix compared with other method of loading metal into carbon.

Transmission electron microscopy (TEM) with high resolution transmission electron microscopy (HRTEM) and electron diffraction (ED) was employed to characterize the microstructure and ultrastructure of materials. ${ }^{26-28}$ The TEM equipped with a heating holder and a hot stage controller allows in situ observations of phenomena, which accelerated the development of metallurgical applications. In 1970, the hot stage TEM was applied to study crystal nucleation in a lithia-silica glassy system. ${ }^{29}$ In 2007, a in situ TEM experiment was used as a guideline to synthesize as-grown ordered CoPt nanoparticles. ${ }^{30}$ So far, in situ TEM is a powerful method for the observation of micro structural phase changes, ${ }^{31}$ nucleation, ${ }^{32}$ growth and dissolution processes. ${ }^{33,34}$

Here, TEM combined with in situ hot stage technique was applied to directly observe the transition from MOF to metal NPs. Through in situ TEM experiment, the nanocrystals of Nintca precursor (ntca $=1,4,5,8$-naphthalenetetracarboxylic acid) are pyrolyzed under the temperature of 400,500 , or $600{ }^{\circ} \mathrm{C}$ to synthesize abundant Ni-NPs embedded in hierarchically porous carbon composites. Furthermore, the as-prepared samples show high catalytic activity and stability for the reduction of 4nitrophenol (4-NP) to 4-aminophenol (4-AP) with $\mathrm{NaBH}_{4}$ in aqueous conditions. More importantly, Ni@C-600, which has nickel contents of $72.8 \%$, shorten the reduction time to $3.5 \mathrm{~min}$ with high conversion of nearly $100 \%$. When the catalyst is applied to recycle after being separated from the reaction by an extern magnet, it still keeps high conversion of $92 \%$ after 8 cycles, addressing the high stability of the composites.

\section{Experimental}

\section{Synthesis of 1,4,5,8-naphthalenetetracarboxylic acid (NTCA)}

1,4,5,8-Naphthalenetetracarboxylic dianhydride (NTCDA, 1 mmol) was dissolved in a aqueous solution of $\mathrm{NaOH}$ under stirring at $60-70{ }^{\circ} \mathrm{C}$. After hydrolyzing for $1 \mathrm{~h}, 1 \mathrm{M} \mathrm{HCl}$ was added dropwise until a precipitate formed and $\mathrm{pH}$ was about 23. Then the precipitate was filtered and dried at room temperature. $^{35}$

\section{Synthesis of Ni-ntca}

$\mathrm{Ni}\left(\mathrm{NO}_{3}\right)_{2} \cdot 6 \mathrm{H}_{2} \mathrm{O}(0.116 \mathrm{~g}, 0.4 \mathrm{mmol})$ was dissolved in a mixture solvent of $1.4 \mathrm{~mL}$ of dimethylformamide (DMF), $1.4 \mathrm{~mL}$ of ethanol, $1.4 \mathrm{~mL}$ of water. Then NTCA $(0.015 \mathrm{~g}, 0.05 \mathrm{mmol})$ was added into the above solvent under sonicating. The resulting mixture was transferred into a Teflon autoclave and maintained at $100{ }^{\circ} \mathrm{C}$ for 3 days. The grown powders were washed with DMF and distilled water several times and dried at room temperature. The as-prepared powders were called as Ni-ntca.

\section{Synthesis of nickel@carbon hybrids}

In a typical synthesis, the precursor $\mathrm{Ni}$-ntca were paved in a ceramic boat and placed into a furnace. Carbonizing the powder under a nitrogen flow and heating to different temperatures with a heating rate of $5{ }^{\circ} \mathrm{C} \mathrm{min}^{-1}$. After the pre-set temperature reached, the powders were annealed for $3 \mathrm{~h}$. These products were donated as $\mathrm{Ni@C-X}(X$ is considered as pre-set temperature).

\section{Catalytic tests on reduction of 4-NP}

In the quartz cell, pipetting $2.05 \mathrm{~mL}$ of deionized water, followed by the addition of $60 \mu \mathrm{L}$ of 4-nitrophenol solution (5 $\mathrm{mM}$ ), and the $0.65 \mathrm{~mL}$ of $\mathrm{NaBH}_{4}$ aqueous solution $(0.2 \mathrm{M})$ was added to the mixture and the color changed to deep yellow solution. Then the catalyst suspension $\left(50 \mu \mathrm{L}, 6 \mathrm{mg} \mathrm{mL}^{-1}\right)$ was added to the above mixture solution. During the reaction, the reaction was taken at $1 \mathrm{~min}$ intervals and analyzed by UV/vis spectroscopy, which were recorded in the scanning range of 250-500 $\mathrm{nm}$ at room temperature. For recycling, the catalyst was recovered using an external magnetic field for the next cycle.

\section{The in situ hot stage experiment}

A small amount of Ni-ntca was dispersed in ethanol, after ultrasonic treatment, dripped onto a copper grid supporting holey carbon film. A single crystal of Ni-ntca was selected to observe the transition under beam irradiation. The TEM images and Selected Area Electron Diffraction (SAED) patterns of Nintca were taken every 5 minutes. The parameters of this experiment were listed in Table 1.

\section{Characterization}

The X-ray diffraction patterns were recorded on a SHIMADZU LabX XRD-6000 diffractometer with $\mathrm{Cu}-\mathrm{K} \alpha$ radiation $(\lambda=$ $1.5418 \AA$ ) in the $2 \theta$ range of $10-80^{\circ}$ with a step size of $0.02^{\circ}$ and a time of 4 second per step. Raman spectra were measured on an inVia microscopic confocal laser Raman spectrometer. We investigated the morphology with a JEOS JSM-6510 and microstructure of the particles with a JEM-2100 TEM system. An in situ hot stage holder and heater control from GatansmartSet Model 901 was used in this study. Thermogravimetric analysis (TGA) was performed using a SHIMADZU DTG-60 thermal analyzer system at a heating rate of $10{ }^{\circ} \mathrm{C} \mathrm{min}^{-1}$ from $50{ }^{\circ} \mathrm{C}$ to $600{ }^{\circ} \mathrm{C}$ under dry air atmosphere with a flow rate of $30 \mathrm{~mL} \mathrm{~min}^{-1}$. Nitrogen adsorption-desorption measurements were measured with a Micro Meritics TriStar II 3020 surface area and pore size analyzer at $77 \mathrm{~K}$. The absorbance of 4-NP was obtained on a UV-2450 UV/vis spectrophotometer.

Table 1 The parameters of the beam irradiation experiment

\begin{tabular}{ll}
\hline Condition & Unit \\
\hline High tension & $200 \mathrm{kV}$ \\
Spot size & Spot 5 \\
Current density & $1.1-8.7 \mathrm{pA} \mathrm{cm}^{2}$ \\
Exposure time & $45 \mathrm{~s} \mathrm{M}$ \\
Magnification & $50 \mathrm{k}$
\end{tabular}




\section{Results and discussion}

The Ni-ntca crystals were synthesized by hydrothermal process. It can be easily obtained by adding nickel nitrate and NTCA into a mixture solvent, and then heated in a Teflon autoclave for $72 \mathrm{~h}$. The light brown crystal powders were analyzed by X-ray diffraction (XRD) measurement (Fig. S1 $\dagger$ ). The relative intensities and peak positions in the XRD patterns were in good agreement with the predicted diffraction patterns, revealing the high crystalline of the synthesized Ni-ntca. ${ }^{36}$

This moment, a hot stage was used for in situ experiments in TEM to directly observe the changes of the Ni-ntca. Lots of TEM images and the corresponding diffraction (ED) patterns of the $\mathrm{Ni}$-ntca particles were taken as elevating the carbonization temperature in TEM (Fig. 1). The single crystal was displayed in Fig. 1a, and the ED pattern of crystal showed us high degree of crystallinity in Fig. 1b. Then, we raised the temperature in $100{ }^{\circ} \mathrm{C}$ increments, and stopped 5 minutes at each temperature. At a temperature of $300{ }^{\circ} \mathrm{C}$, the nanoparticles (black dots) emerged in the carbon (Fig. 1c), which confirmed by the appearance of diffraction rings (Fig. 1d). The corresponding crystalline diffraction rings of (111) and (200) in the SAED pattern indicated the borning of Ni NPs. From $400{ }^{\circ} \mathrm{C}$ to $600{ }^{\circ} \mathrm{C}$, the crystallization degree of the Ni NPs and the stability of the carbon gradually enhanced (Fig. 1e-h). When the temperature exceeded $600{ }^{\circ} \mathrm{C}$, the Ni NPs were unstable and came out of the carbon to form large particles (Fig. 1h). When extending the holding time of 5 minutes to 20 minutes, we found that the results as shown in Fig. $\mathrm{S} 2 \dagger$ were similar to those from 5 minutes. As it is well known the MOFs materials are sensitive to the beam irradiation, we tried to explain that the beam was not playing a leading role in the process of in situ experiment, and the following work was performed using TEM. The Ni-ntca was irradiated under beam for a long time using TEM. The TEM image and SAED patterns of the crystal were collected on time during irradiation and contrasted with Fig. 1d, there was no appearance of Ni NPs within 2 hours, addressing that beam didn't work for the transition from MOFs to metal NPs, while led to the collapse of MOFs structure (Fig. S3†). Following, these thermal phenomena became a reference for us in preparing $\mathrm{Ni@C-X}$ composite series by carbonizing the Ni-ntca at $300{ }^{\circ} \mathrm{C}$, $400{ }^{\circ} \mathrm{C}, 500{ }^{\circ} \mathrm{C}$, and $600{ }^{\circ} \mathrm{C}$ under a nitrogen flow.

The XRD patterns of a series of samples after carbonization were showed in Fig. 2 and S4. $\dagger$ One low broad peak centered at $2 \theta=25^{\circ}$ assigned to amorphous carbon, ${ }^{37}$ the other three

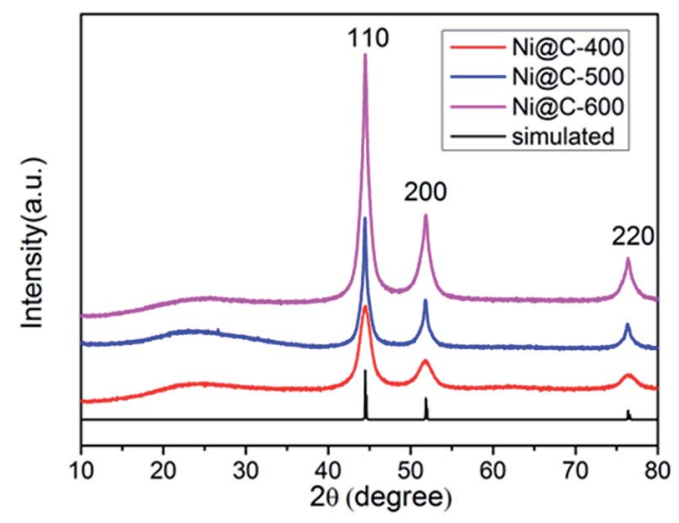

Fig. 2 PXRD patterns of Ni@C-400, Ni@C-500, Ni@C-600 and the simulated data of cubic phased Ni (JCPDS no. 04-0850).
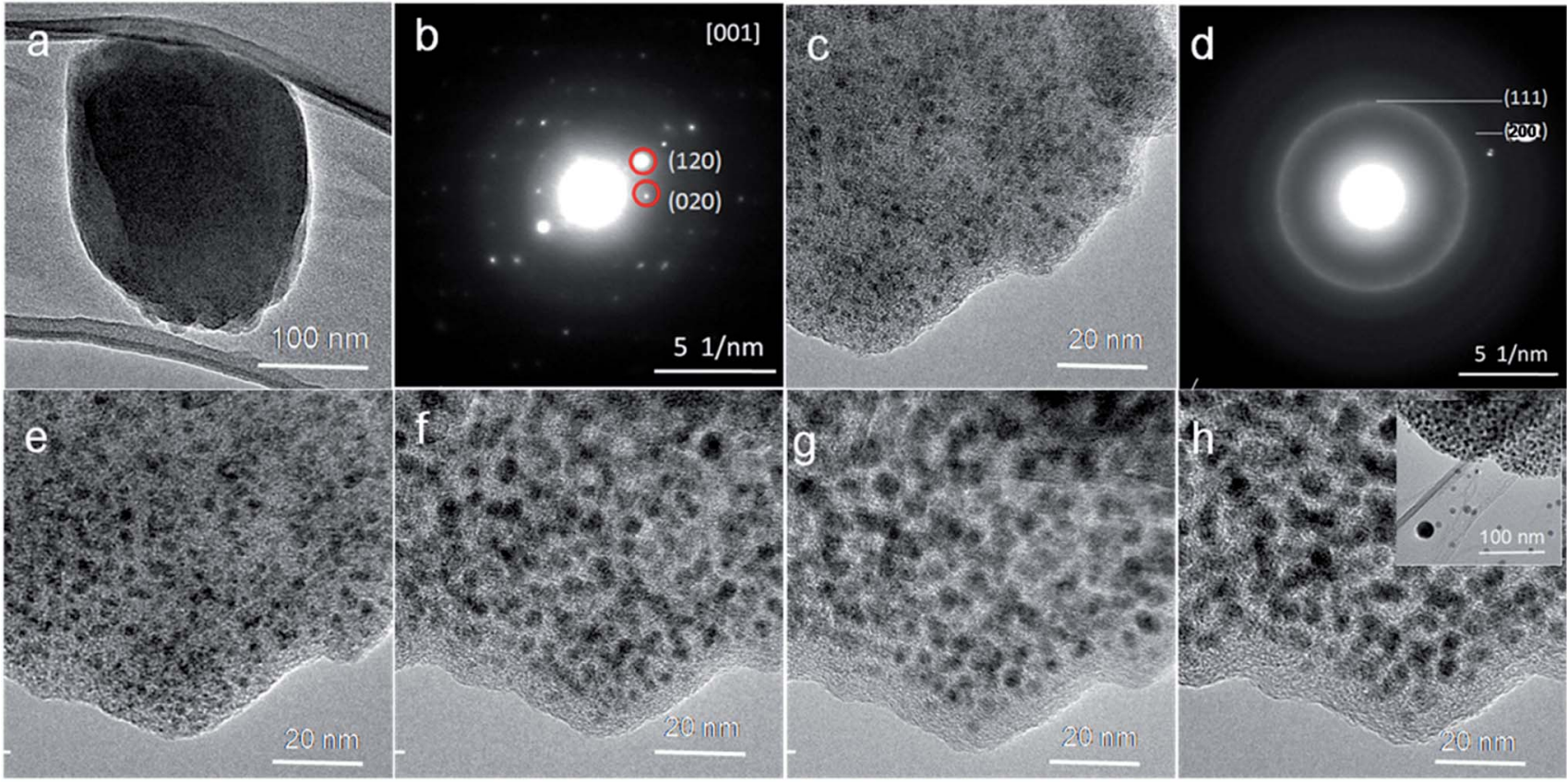

Fig. 1 The hot stage TEM images at (a) room temperature, (b) Selected Area Electron Diffraction (SAED) pattern of Ni-ntca in [001] zone axe, (c) $300{ }^{\circ} \mathrm{C}$, (d) SAED pattern of (c), (e) $400{ }^{\circ} \mathrm{C}$, (f) $500{ }^{\circ} \mathrm{C}$, (g) $600{ }^{\circ} \mathrm{C}$, and (h) $700{ }^{\circ} \mathrm{C}$. 
prominent peaks near at $2 \theta=44.3^{\circ}, 51.6^{\circ}$ and $76.2^{\circ}$, being well assigned to the reflections of the (111), (200) and (220) crystalline planes of cubic-phased Ni (JCPDS no. 04-0850), respectively, were detected (Fig. 2). When pyrolyzing the Ni-ntca at $400{ }^{\circ} \mathrm{C}$, $500{ }^{\circ} \mathrm{C}$ and $600{ }^{\circ} \mathrm{C}$ in a nitrogen flow, the $\mathrm{Ni}$-ntca have been completely converted to amorphous carbon and cubic-phased Ni NPs, and there was no peaks showing Ni been oxidized to nickel monoxide (NiO). However, the peaks of Ni@C-300 were different from the cubic-phased $\mathrm{Ni}$ and were proven to be not pure Ni nanoparticles (Fig. S4†).

As seen in Fig. 3, a broad D band appeared at $1340 \mathrm{~cm}^{-1}$ which ascribed to the disorder-induced mode, while a relatively sharp $\mathrm{G}$ band appeared at $1575 \mathrm{~cm}^{-1}$ which ascribed to the $\mathrm{E}_{2 \mathrm{~g}}$ mode from the $\mathrm{sp}^{2}$ carbon. The relative ratios of $\mathrm{D}$ bands to $\mathrm{G}$ bands $\left(I_{\mathrm{D}} / I_{\mathrm{G}}\right)$ in Raman spectra, was 0.8 , indicating the crystallization degree of graphitic carbon. This $I_{\mathrm{D}} / I_{\mathrm{G}}$ ratio was comparable to those measured for GO and $\mathrm{rGO}\left(I_{\mathrm{D}} / I_{\mathrm{G}}=\sim 1\right),{ }^{38}$ indicating that high quality $3 \mathrm{D}$ graphite carbon was formed. Likewise, there was a $2 \mathrm{D}$ band at $2676 \mathrm{~cm}^{-1}$.

To investigate the samples after carbonizing, we characterized the samples by TEM. From the TEM images (Fig. 4a-f), because of nanoscale morphology of $\mathrm{Ni}$-ntca, they were all thermodynamically unstable and able to aggregate, and finally appeared irregularly shapes. After carbonizing, the composites still kept indefinite shapes (Fig. 4a and b). While further magnifying the edge at $300 \mathrm{k}$, the Ni NP were uniformly deposited in the carbon matrix, almost all of the particles were wrapped by thin carbon, thus there was no reunion as well (Fig. 4c and d). The distribution range of Ni NPs was mainly distributed from $4 \mathrm{~nm}$ to $7 \mathrm{~nm}$ measured by TEM (Fig. S5 $\dagger$ ). To investigate crystallization degree of metal $\mathrm{Ni}$, we continued to magnify the thin edge to $500 \mathrm{k}$, and clearly observed metal lattice fringe, indicating that each particle had a single crystalline structure (Fig. 4e and f). The distance of the adjacent lattice fringes (marked by the white arrows) was calculated to be about $0.203 \mathrm{~nm}$, corresponding well to the $d_{111}$ spacing of cubic Ni. The corresponding fast Fourier transform (FFT) patterns were showed in the inset in Fig. 4e and f. Ni NPs were used as catalysts to induce the graphitization of carbon during the carbonization, thus three-dimensional graphite layers were readily produced around the metal $\mathrm{Ni}$, which was in accordance

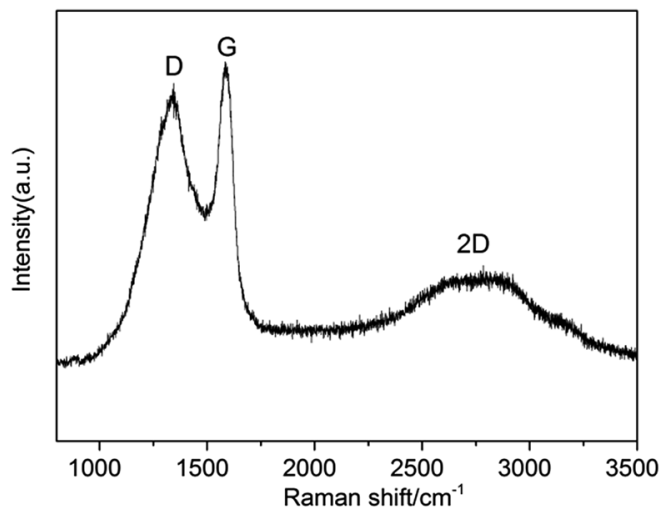

Fig. 3 Raman pattern of Ni@C-600.



Fig. 4 TEM images of NiaC - 600 at 100k ( $a$ and b), 300k (c and d), and $500 \mathrm{k}((\mathrm{e})$ and (f), inset: FFT-ED pattern).

with the results of Raman. The TEM images of Ni@C-400 and Ni@C-500 were placed in Fig. S6. $\dagger$ The images of scanning transmission electron microscope (STEM) were showed in Fig. S7, $\uparrow$ further confirming the uniform distribution of Ni@C$X$. From the TEM results, the synthetic Ni@C- $X$ composites with a structure of thin 3D graphite carbon and plentiful Ni NPs will enhance the catalytic activity. The resultant samples were all composed of uniformly dispersed Ni NPs and carbon matrix.

To calculate the loading content of Ni NPs in the nanoporous carbon, the thermo gravimetric analysis (TGA) was carried out in the temperature range of $50-600^{\circ} \mathrm{C}$ under dry air atmosphere at a heating rate of $10{ }^{\circ} \mathrm{C} \mathrm{min}^{-1}$. From the TGA curves (Fig. 5), the nickel loading amounts of three samples were about $68.6 \%$, $72.1 \%$ and 72.9\% for Ni@C-400, Ni@C-500, Ni@C-600, respectively. Obviously, during carbonization, the metal contents increased while the carbon was generally declined as elevating the temperature. In the test of catalytic reduction of 4-nitrophenol (4-NP), the more Ni loading quality will acquire more excellent catalytic performance.

The $\mathrm{N}_{2}$ adsorption/desorption isotherms of Ni@C- $X$ were measured to explore porous structure (Fig. 6). Three samples exhibited typical type IV isotherms with a hysteresis loop, showing the existence of mesoporous (Fig. 6a). The pore size 


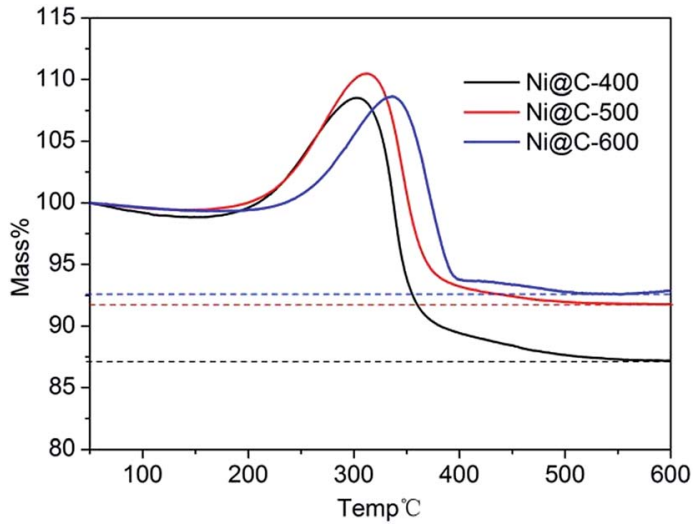

Fig. 5 TGA curves of NiaC-400 (black), Ni@C-500 (red), and Ni@C600 (blue).
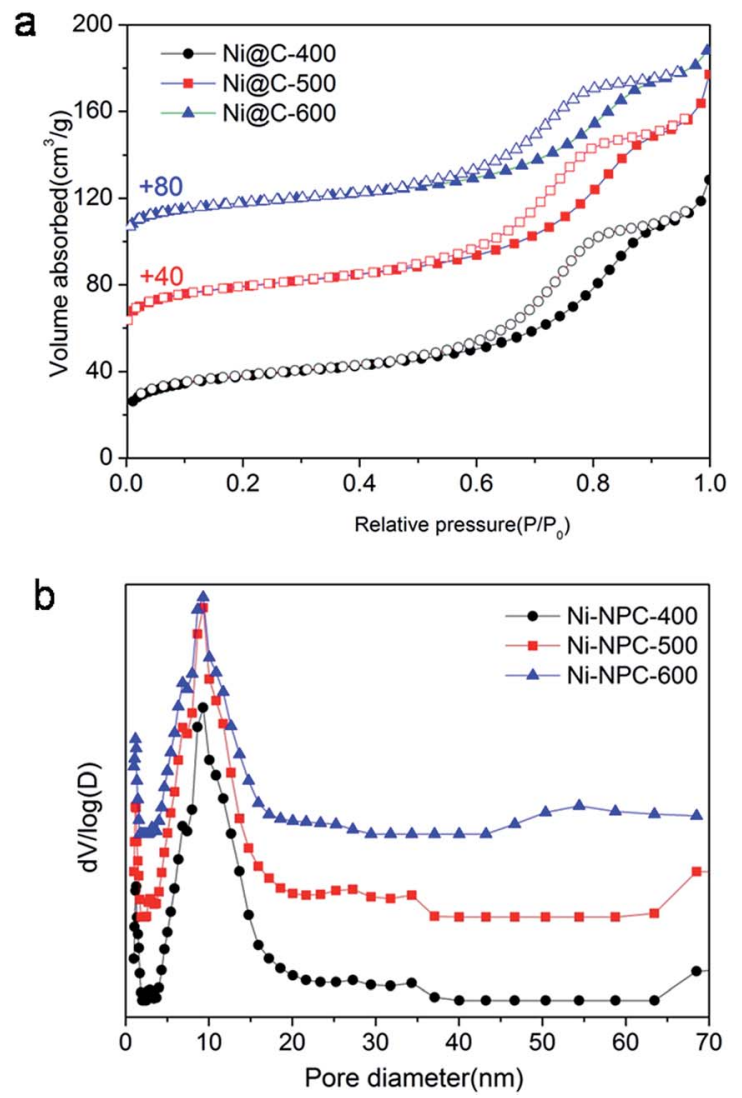

Fig. 6 (a) $\mathrm{N}_{2}$ absorption-desorption isotherms and (b) their corresponding pore size distributions $\left(\mathrm{N}_{2}\right.$ absorption-desorption isotherms for Ni@C-500 and Ni@C-600 are vertically offset by 40 and $80 \mathrm{~cm}^{3}$ $\mathrm{g}^{-1}$ ).

distribution curves (Fig. 6b) indicated that the mesoporous sizes were centered at around $9.0 \mathrm{~nm}$, the microporous sizes were centered at about $1 \mathrm{~nm}$, and the macroporous still existed in the samples, however, the dominating porous structure was mesopores. Brunauer-Emmett-Teller (BET) specific surface area of $138 \mathrm{~m}^{2} \mathrm{~g}^{-1}, 142 \mathrm{~m}^{2} \mathrm{~g}^{-1}$ and $139 \mathrm{~m}^{2} \mathrm{~g}^{-1}$ were obtained for Ni@C-400, Ni@C-500, Ni@C-600, respectively. Furthermore, the $\mathrm{N}_{2}$ absorption isotherm of the $\mathrm{Ni}-\mathrm{ntca}$ was also shown in Fig. S8. $\uparrow$ The BET surface area of the Ni-ntca was $100 \mathrm{~m}^{2} \mathrm{~g}^{-1}$ and the pore size distribution showed it was microspores.

At the end, we measured the catalytic activity of $\mathrm{Ni@C-} X$ for reduction of 4-NP. In recent years, the reduction of 4-nitrophenol (4-NP) to 4-aminophenol (4-AP) with $\mathrm{NaBH}_{4}$ in aqueous solution has become such a model reaction that many groups used to test catalytic performance. We can monitor accurately through UV/vis spectroscopy. It was clearly that 4-NP had a strong absorption peak at $400 \mathrm{~nm}$ in an aqueous solution of $\mathrm{NaBH}_{4}$ and the absorption peak shifted to $295 \mathrm{~nm}$ addressing the formation of 4-aminophenol (4-AP). The color of 4-NP solution was light yellow, with mixing $\mathrm{NaBH}_{4}$ into solution and turned into light yellow, with adding the catalyst composite and turned into colorless. ${ }^{39,40}$ The whole catalytic progress was measured regularly by UV/vis spectroscopy. Fig. 7a displayed the typical evolution of the UV/vis spectra with time for the sample. After the $0.3 \mathrm{mg}$ catalyst is added to solution, the reaction immediately proceeded and we measured the absorbance curve every 1 minute. The intensity of peaks of the nitro compound at $400 \mathrm{~nm}$ decreased sharply, while the aminophenol at $295 \mathrm{~nm}$ increased. No other peak appeared, indicating no side reaction had taken place. When the peak belong to the nitro compound was no longer observed and the corresponding color changed from yellow to colorless, demonstrating the catalytic reduction of 4-NP completed. The reduction time of converting 4-NP to 4AP over Ni@C-600 was 3.5 min (Fig. 7c), which was faster than Ni@C-400 of 6 min (Fig. 7a) and Ni@C-500 of 4 min (Fig. 7b).

According to the knowledge of physical chemistry principles, the above catalytic reduction reactions followed the LangmuirHinshelwood apparent first order kinetics mode without thinking about an amounts of $\mathrm{NaBH}_{4}$. The equation is described as $\mathrm{d} C_{t} / \mathrm{d} t=\mathrm{d} A_{t} / \mathrm{d} t=k_{\text {app }} C_{t} t=k_{\text {app }} A_{t} t$ or $\ln \left(C_{t} / C_{0}\right)=\ln \left(A_{t} / A_{0}\right)=$ $k_{\text {app }} t, C_{t}$ and $A_{t}$ are the concentration and absorbance of 4-NP at $400 \mathrm{~nm}$ at time $t, C_{0}$ and $A_{0}$ are the initial concentration and absorbance of $4-\mathrm{NP}$ at $400 \mathrm{~nm}$, and $k_{\text {app }}$ is the apparent rate constant. ${ }^{41}$ Fig. 7d showed the concentration of $C_{t}(C$ at time $t)$ to its initial value $C_{0}\left(C_{t} / C_{0}\right)$ versus reaction time for the reduction of 4-NP over the catalyst of Ni@C-400, Ni@C-500 and Ni@C-600. It can be found that the resultant catalysts were highly active for catalyzing 4-NP reduction with nearly $100 \%$ efficiency. Fig. 7e showed plots of $\ln \left(C_{t} / C_{0}\right)$ versus reaction time. The respective rate constant was calculated to be $22.5,20.8$ and $12.0 \times 10^{-3} \mathrm{~s}^{-1}$. The rate constant per gram of Ni@C- $X(K)$ was then calculated, the activity factors $K$ were calculated to be $40.0,69.3$ and $75.0 \mathrm{~s}^{-1}$ $\mathrm{g}^{-1}$ for Ni@C-400, Ni@C-500 and Ni@C-600, respectively. Obviously, Ni@C-600 exhibited high catalytic activity compared with Ni@C-500 and Ni@C-400, which benefited from its large nickel loading amounts and high crystallinity with quick accessibility in and out of the porous carbon matrix. The turnover frequency (TOF) was further evaluated, which was defined as the number of moles of 4-NP reduced per mole of nickel per hour (Table 2). The rate constant and TOF values of Ni@C- $X$ were much bigger than the previously reported Ni-NPC-600 and other Ni-based catalysts ${ }^{\mathbf{2 1 , 3 9 , 4 2 , 4 3}}$ (Table 2), which can be summarized to following factors: (1) the smaller Ni NPs, which supplied the catalytic reduction with a larger reaction area and more active 

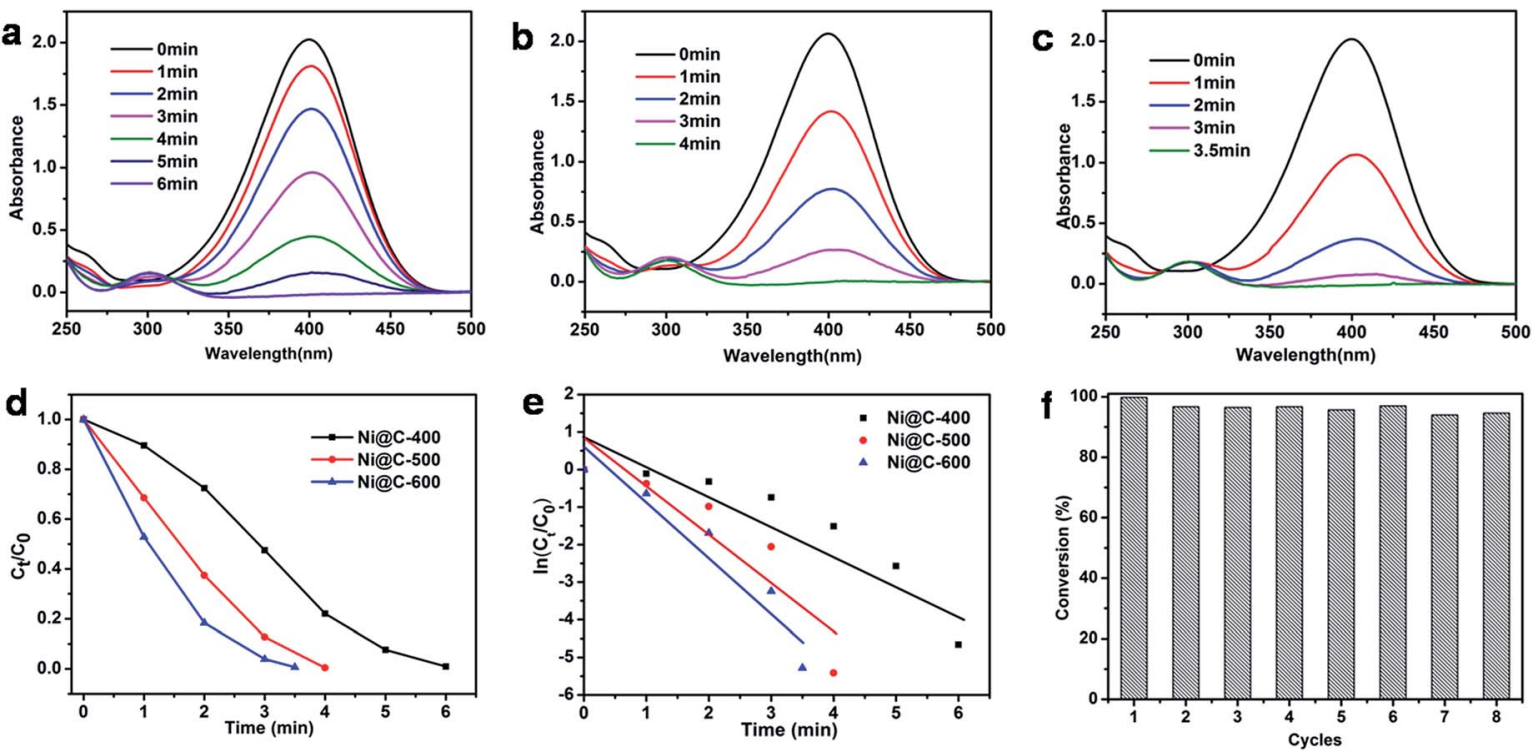

Fig. 7 Successive UV-vis absorption spectra during the catalytic reduction of 4-NP using (a) Ni@C-400, (b) Ni@C-500, (c) Ni@C-600 as catalyst; (d) $C_{t} / C_{0}$ versus reaction time for the reduction of $4-\mathrm{NP}$ and (e) plot of $\ln \left(C_{t} / C_{0}\right)$ against the reaction time of 4-NP reduction over NiaC-400 (black line), Ni@C-500 (red line), Ni@C-600 (blue line); (f) the reusability of Ni@C-600 catalyst.

Table 2 Textual properties, kinetic constants and turnover frequencies of the catalysts

\begin{tabular}{|c|c|c|c|c|c|c|}
\hline Catalyst & $\begin{array}{l}\text { Ni loading } \\
\text { (wt\%) }\end{array}$ & $S_{\mathrm{BET}}\left(\mathrm{m}^{2} \mathrm{~g}^{-1}\right)$ & $k_{\mathrm{app}} \times 10^{-3}\left(\mathrm{~s}^{-1}\right)$ & $K^{b}\left(\mathrm{~s}^{-1} \mathrm{~g}^{-1}\right)$ & $\operatorname{TOF}^{c}\left(\mathrm{~h}^{-1}\right)$ & Reference \\
\hline $\mathrm{Ni@C-400}$ & $68.6^{a}$ & 138 & 12.0 & 40.0 & 2.1 & This work \\
\hline Ni@C-600 & $72.9^{a}$ & 139 & 22.5 & 75.0 & 6.6 & This work \\
\hline Ni-NPC-600 & - & 169 & 5.9 & 2.95 & 0.19 & 34 \\
\hline $\mathrm{Ni}_{0.1} / \mathrm{NPC}$ & 46.5 & 389 & 2.0 & 6.7 & 0.468 & 21 \\
\hline $\mathrm{Ni}_{0.52} \mathrm{Sb}_{0.48} / \mathrm{SBA}-15$ & 2.85 & 416 & 3.7 & 140 & - & 43 \\
\hline $\mathrm{Ni} / \mathrm{SiO}_{2}$ & 14.6 & 185 & 4.5 & 1.5 & 12.2 & 39 \\
\hline
\end{tabular}

${ }^{a}$ Estimated by TGA. ${ }^{b}$ The activity factors $[K]$ : the rate constant per gram. ${ }^{c}$ TOF (turnover frequency): moles of 4 -NP converted per mole Ni per hour.

sites for reduction; (2) the larger loading content of Ni NPs with more catalytic sites were beneficial to enhanced the catalytic performance; (3) the carbon surrounded Ni NPs were thinner and had a 3D structure, making the 4-nitrophenolate ion rapidly pass through and reach; (4) the easier hydrophilic characteristic due to a little amounts of carbon, which made it convenient to absorb borohydride anion on the surface of Ni NPs.

To evaluate the reusability of our catalyst, the successive cycles of the catalytic reduction were carried out. As shown in Fig. 7f, the catalyst can be successfully used after being separated from reaction by an extern magnet, and still kept high activity and striking conversion of $92 \%$ after 8 cycles. The large conversion efficiency indicated the Ni NPs were stable and protected by the wrapped carbon. The TEM images of Fig. S9 $\dagger$ told us there was no aggregation of Ni NPs, and structure and morphology were well maintained, fully demonstrating the good stability of the catalyst.

\section{Conclusions}

In conclusion, we selected a new Ni-ntca as the effective precursor to construct composites structure of magnetic nickel NPs embedded in hierarchically porous carbon matrix. The pyrolysis temperature was determined with transform of surface and the corresponding electron diffraction (ED) of the crystal during directly observing the transition of a Ni-ntca to $\mathrm{Ni}$ NPs. The product of $600{ }^{\circ} \mathrm{C}$ (Ni@C-600) exhibited excellent catalysis activity and remarkable durability for the reduction of 4-NP to 4-AP in mild condition. The nickel loading contents of Ni@C-600 were as high as $72.8 \%$, which shortened catalysis reaction time to $3.5 \mathrm{~min}$ and possessed nearly $100 \%$ conversion. Moreover, the catalyst still remained large conversion efficiency of $92 \%$ after 8 cycles. It is believed that these results will further facilitate the exploration of the technique of the TEM combined with in situ hot stage as a powerful tool in the carbonization of MOFs to obtain derivations of MOFs with different applications. 


\section{Acknowledgements}

This work was supported by National Natural Science Foundation of China (21390394, 21571079, 21621001, 21571076, and 21571078), “111” project (B07016), and Guangdong Science and Technology Department Project (2013B090200052 and 2012D0501990028). Q. F. acknowledges the Thousand Talents program (China).

\section{Notes and references}

1 H. Li, M. Eddaoudi, M. O'Keeffe and O. M. Yaghi, Nature, 1999, 402, 276-279.

2 G. Férey, Chem. Soc. Rev., 2008, 37, 191-214.

3 H. C. Zhou, J. R. Long and O. M. Yaghi, Chem. Rev., 2012, 112, 673-674.

4 N. Stock and S. Biswas, Chem. Rev., 2012, 112, 933-969.

5 Y. B. He, B. Li, M. O'Keeffe and B. L. Chen, Chem. Soc. Rev., 2014, 43, 5618-5656.

6 J. W. Liu, L. F. Chen, H. Cui, J. Y. Zhang, L. Zhang and C. Y. Su, Chem. Soc. Rev., 2014, 43, 6011-6061.

7 Q. R. Fang, G. S. Zhu, Z. Jin, Y. Y. Ji, J. W. Ye, M. Xue, H. Yang, Y. Wang and S. L. Qiu, Angew. Chem., 2007, 119, 6758-6762.

8 S. L. Qiu, M. Xue and G. S. Zhu, Chem. Soc. Rev., 2014, 43, 6116-6140.

9 Z. J. Zhang, W. Shi, Z. Niu, H. H. Li, B. Zhao, P. Cheng, D. Z. Liao and S. P. Yan, Chem. Commun., 2011, 47, 64256427.

10 J. Y. Lee, O. K. Farha, J. Roberts, K. A. Scheidt, S. B. T. Nguyen and J. T. Hupp, Chem. Soc. Rev., 2009, 38, 1450-1459.

11 H. Xu, F. Liu, Y. J. Cui, B. L. Chen and G. D. Qian, Chem. Commun., 2011, 47, 3153-3155.

12 J. Tang, R. R. Salunkhe, J. Liu, N. L. Torad, M. Imura, S. Furukawa and Y. Yamauchi, J. Am. Chem. Soc., 2015, 137, 1572-1580.

13 B. Liu, H. Shioyama, T. Akita and Q. Xu, J. Am. Chem. Soc., 2008, 130, 5390-5391.

14 S. R. Chen, M. Xue, Y. Q. Li, Y. Pan, L. K. Zhu and S. L. Qiu, J. Mater. Chem. A, 2015, 3, 20145-20152.

15 Y. Pan, M. Xue, M. Y. Chen, Q. R. Fang, L. K. Zhu, V. Valtchev and S. L. Qiu, Inorg. Chem. Front., 2016, 3, 1112-1118.

16 Y. Q. Li, T. Ben, B. Y. Zhang, Y. Fu and S. L. Qiu, Sci. Rep., 2013, 3, 2420-2426.

17 X. Y. Li, C. M. Zeng, J. Jiang and L. H. Ai, J. Mater. Chem. A, 2016, 4, 7476-7482.

18 S. Ma, G. A. Goenaga, A. V. Call and D. J. Liu, Chem.-Eur. J., 2011, 17, 2063-2067.

19 J. K. Sun and Q. Xu, Energy Environ. Sci., 2014, 7, 2071-2100.

20 K. Shen, X. D. Chen, J. Y. Chen and Y. W. Li, ACS Catal., 2016, 6, 5887-5903.
21 Y. Yang, Y. Zhang, C. J. Sun, X. S. Li, W. Zhang, X. H. Ma, Y. Ren and X. Zhang, ChemCatChem, 2014, 6, 3084-3090.

22 W. Xia, R. Q. Zou, L. An, D. G. Xia and S. J. Guo, Energy Environ. Sci., 2015, 8, 568-576.

23 H. Y. Niu, S. L. Liu, Y. Q. Cai, F. C. Wu and X. L. Zhao, Microporous Mesoporous Mater., 2016, 219, 48-53.

24 R. Q. Fang, R. Luque and Y. W. Li, Green Chem., 2016, 18, 3152-3157.

25 F. Ke, J. F. Zhu, L. G. Qiu and X. Jiang, Chem. Commun., 2013, 49, 1267-1269.

26 Z. Liu, T. Ohsuna, O. Terasaki, M. A. Camblor, M. DiazCabaňas and K. Hiraga, J. Am. Chem. Soc., 2001, 123, 53705371.

27 Y. Sakamoto, M. Kaneda, O. Terasaki, D. Y. Zhao, J. M. Kim, G. Stuckyk, H. J. Shin and R. Ryoo, Nature, 2000, 408, 449453.

28 Y. Han, D. L. Zhang, L. L. Chng, J. L. Sun, L. Zhao, X. D. Zou and J. Ying, Nat. Chem., 2009, 1, 123-127.

29 D. L. Kinser and L. L. Hench, J. Mater. Sci., 1970, 5, 369-373.

30 D. Alloyeau, C. Langlois, C. Ricolleau1, Y. Le Bouar and A. Loiseau, Nanotechnology, 2007, 18, 375301-375306.

31 L. J. Bowen, R. J. Weston, T. G. Carruthers and R. J. Brook, J. Mater. Sci., 1978, 13, 341-350.

32 A. Garg and J. M. Howe, Acta Mater., 1991, 39, 1925-1937.

33 B. William and H. James, Philos. Mag. A, 1997, 75, 16411663.

34 D. Xu, D. L. Zhang, H. B. Zou, L. K. Zhu, Q. R. Fang and S. L. Qiu, Chem. Commun., 2016, 52, 10513-10516.

35 U. Rana, K. Chakrabarti and S. Malik, J. Mater. Chem., 2011, 21, 11098-11100.

36 L. F. Chen, J. Zhang, L. J. Song and Z. F. Ju, Inorg. Chem. Commun., 2005, 8, 555-558.

37 B. Liu, H. Shioyama, H. L. Jiang, X. B. Zhang and Q. Xu, Carbon, 2010, 48, 456-463.

38 J. Gong, J. Liu, L. Ma, X. Wen, X. C. Chen, D. Wan, H. O. Yu, Z. W. Jiang, E. Borowiak-Palen and T. Tang, Appl. Catal., B, 2012, 117-118, 185-193.

39 Z. Y. Niu, S. H. Zhang, Y. B. Sun, S. L. Gai, F. He, Y. L. Dai, L. Li and P. P. Yang, Dalton Trans., 2014, 43, 16911-16918.

40 W. C. Pan, S. H. Zhang, F. He, S. L. Gai, Y. B. Sun and P. P. Yang, CrystEngComm, 2015, 17, 5744-5750.

41 M. Schrinner, M. Ballauff, Y. Talmon, Y. Kauffmann, J. Thun, M. Möller and J. Breu, Science, 2009, 323, 617-620.

42 W. Zuo, G. Q. Yu and Z. P. Dong, RSC Adv., 2016, 6, 1174911753.

43 V. S. Marakatti and S. C. Peter, New J. Chem., 2016, 40, 54485457. 